\title{
Pela Introdução de uma Educação Ambiental Ecocêntrica Vantagens e Desafios ${ }^{1}$
}

\author{
Ana Stela Câmara \\ Graduação (2003-2007), Mestrado (2008-2010) e Doutorado (2011-2016) em Direito pela Universidade Federal do Ceará. \\ Professora de Metodologia da Pesquisa e Direito Ambiental no Centro Universitário Christus (2011) e coordenadora geral de \\ Pesquisa e Extensão na mesma instituição (2016). Realiza pesquisas inter-relacionando as seguintes grandes áreas: Direito \\ Constitucional Ambiental, Desenvolvimento Sustentável e Ética. Membro da Associação Brasileira de Professores de Direito \\ Ambiental (Aprodab).emaildastela@gmail.com
}

RESUMO

O presente trabalho tem por objetivo identificar vantagens e desafios à introdução de uma educação ambiental ecocêntrica no Brasil. A relevância da análise reside nas evidências de insuficiência dos parâmetros oferecidos pela tradição antropocêntrica dominante em lidar com a preservação ambiental, haja vista o constante aumento da degradação ambiental e da perda de biodiversidade. Acredita-se que a ênfase na perspectiva inter-relacional levantada por uma educação ambiental de orientação ecocêntrica, possa ser útil para subverter a lógica de exploração desregrada e de proteção fragmentada do meio ambiente e ampliar a percepção do caráter transfronteiriço e intertemporal dos fenômenos ambientais. A metodologia é analítica e descritiva, embasando-se em fontes bibliográficas e documentais. Conclui-se que as vantagens de adoção do modelo ecocêntrico são promissoras, porém os desafios são muitos, pois a Política Nacional de Educação Ambiental ainda tem baixo nível de execução em todas as suas esferas e suas ações normalmente não privilegiam a sensibilização para o funcionamento sistêmico do ambiente.

Palavras-chave: Efetividade do direito fundamental ao meio ambiente. Educação ambiental. Ecocentrismo.

FOR THE IMPLEMENTATION OF AN ECOCENTRIC ENVIRONMENTAL EDUCATION: BENEFITS AND CHALLENGES

ABSTRACT

This study aims to identify benefits and challenges to the introduction of an ecocentric environmental education in Brazil. The relevance of the analysis is the evidence of weaknesses in the parameters offered by the dominant anthropocentric tradition in dealing with environmental preservation, given the steady increase in environmental degradation and biodiversity loss. It is believed that the emphasis on the interrelation perspective raised by environmental education ecocentric can be useful to subvert the unregulated exploitation of logic and fragmented environmental protection and to increase the perception of the cross-border and intertemporal character of environmental phenomena. The methodology is analytical and descriptive, is basing on bibliographical and documentary sources. We conclude that the benefits of adopting the ecocentric model are promising, but the challenges are many, because Environmental Education National Policy still has low level of execution in Brazil in all its spheres and that the actions usually do not favor the sensitization for systemic aspects.

Keywords: Effectiveness of the fundamental right to the environment. Environmental education. Ecocentrism.

\section{SUMÁRIO}

1 Introdução. 20 dever fundamental de promoção da educação ambiental sob o viés não antropocêntrico. 3 Desafios à introdução de uma educação ambiental ecocêntrica. 4 Conclusão. 5 Referências.

Recebido em: $16 / 6 / 2017$

Aceito em: 29/7/2019

${ }_{1}$ O artigo foi publicado nos anais do III Congresso Internacional de Direito na Amazônia, em Porto Velho (RO) em setembro de 2018. 


\section{INTRODUÇÃO}

Mesmo que se conte com um inescapável e lógico objetivo de salvaguardar a vida humana, as descobertas sobre o complexo sistema de organização da vida demonstram que este objetivo, em última instância, não será alcançado a partir de ações superficiais e egoisticamente centradas. Isso evidencia-se pelo insucesso em se reverter a atual tendência de aumento da poluição, de esgotamento de recursos e de perda de biodiversidade.

Assim, esta preocupação deve ser indissociavelmente relacionada à preservação de um conjunto de inter-relações bióticas e abióticas que dão base e servem de abrigo à vida em geral.

Em decorrência do princípio da autopreservação da vida, deve-se reconhecer que todos os seres possuem valor intrínseco, independentemente de sua utilização atual ou potencial pelo ser humano, e interesse em continuar existindo.

Diante da necessidade de uma profunda mudança de cultura civilizatória, percebe-se a importância do fortalecimento da educação ambiental. Isso porque este instrumento é significativamente adequado para o fortalecimento dos vínculos de corresponsabilidade ecológica do Estado e da coletividade, bem como por oferecer condições para que a sociedade civil, o setor produtivo e os próprios agentes públicos se sensibilizem para a necessidade de consideração de uma compreensão integrada do fenômeno da vida, ampliando os horizontes de compreensão da sustentabilidade, visivelmente insuficientes diante de um passivo ambiental persistente. Trata-se, ainda, de fortalecer o liame comunicacional entre as gerações presentes e futuras, indispensável para lidar com a dimensão transtemporal do direito ambiental.

Nesse sentido, o presente trabalho tem por objetivo realizar uma investigação acerca das vantagens e desafios de concretização de uma educação ambiental não antropocêntrica no Brasil, que venha a servir de instrumento de uma mudança de cultura institucional.

Para tanto, utilizou-se metodologia analítica, descritiva, com base em pesquisa bibliográfica e consulta a dados empíricos retirados de fontes oficiais.

\section{O DEVER FUNDAMENTAL DE PROMOÇÃO DA EDUCAÇÃO AMBIENTAL SOB O VIÉS NÃO ANTROPOCÊNTRICO}

A promoção da educação e da conscientização pública sobre as questões atinentes aos problemas ambientais é das mais importantes intervenções que o Poder Público pode realizar em prol da preservação do meio ambiente no Brasil.

Um forte indício que fundamenta esta afirmação é a discussão ocorrida na Conferência de Limoges, na França, em 1990, em que houve o reconhecimento internacional da correlação entre o desconhecimento das legislações ambientais e da insuficiência de níveis adequados de sua efetividade.

Nacionalmente, uma referência importante é o detalhado estudo histórico da evolução da legislação ambiental brasileira, realizado por Ann Helen Wainer, em que se constata que, em diversas épocas, o Brasil contou com dispositivos ambientais muito avançados, mas que eram ineficazes, em virtude dos seguintes aspectos por ela identificados: ausência de senti- 
mento de amor e valorização da coisa pública pela população nacional ${ }^{2}$ e predominância de posturas individualistas e gananciosas no exercício das atividades econômicas, que ofuscaram os interesses coletivos.

Uma das soluções ofertadas pela autora para reverter paulatinamente os efeitos desastrosos dessa construção histórica e cultural está no fomento à educação ambiental obrigatória ${ }^{3}$.

De acordo com Fritjof Capra (CAPRA; LUISI, 2014), a tomada de consciência sobre os princípios organizacionais dos ecossistemas ${ }^{4}$ é um pressuposto básico para que possamos nos sensibilizar para a problemática ecológica e proceder a uma adequação da nossa forma de vida e de organização econômica e política.

Em outras palavras, para ele o processo de alfabetização ecológica é um requisito indispensável não apenas para a consecução da sustentabilidade como uma utopia distante, mas até mesmo para a própria sobrevivência da humanidade nas próximas décadas. ${ }^{5} E s t a$ demanda fica ainda mais evidente quando se esboça a emergência dos riscos civilizatórios e das incertezas quanto ao futuro. Segundo Edgar Morin, "o futuro permanece aberto e imprevisível". 6

Torna-se, assim, inadiável a tarefa de educar e preparar as gerações futuras. A Constituição Brasileira assimilou esta importante demanda ao insculpir, no artigo 225 , VI, como um dos deveres fundamentais do Estado a promoção da educação ambiental "em todos os níveis de ensino e a conscientização pública para a preservação do meio ambiente".

Trata-se de objeto normativo com denso conteúdo de fundamentalidade, tendo em vista representar a interseção entre o direito à educação (artigo 208, CF/88) e o direito ao meio ambiente?.

Esta norma constitucional foi regulamentada pela Lei 9.795, de 27 de abril de 1999, que instituiu a Política Nacional de Educação Ambiental, a qual define, em seu artigo 2으, a educação ambiental como:

os processos por meio dos quais o indivíduo e a coletividade constroem valores sociais, conhecimentos, habilidades, atitudes e competências voltadas para a conservação do meio ambiente, bem de uso comum do povo, essencial à sadia qualidade de vida e sua sustentabilidade (grifou-se).

Quanto ao seu alcance, a própria Constituição determinou que deveria se dar em todos os níveis de ensino da educação formal, e, com o advento da Lei 9.795/1999, foi ampliada também para a educação não formal, assegurando, em seu artigo 3ㅇ, que todos têm direito à educação ambiental.

\footnotetext{
2 Trata-se de sintoma antigo, que pode ser constatado desde os sermões do Padre Antônio Vieira, que avisava ao Rei que os seus próprios ministros não vinham ao Brasil buscar o bem, mas, sim, os bens. "Em consequência, chegaram, em nossas terras, grandes contingentes humanos de baixa qualidade intelectual e moral que se aventuravam em vir para cá trabalhar e se estabelecer. Cf. WAINER, Ann Helen. Legislação Ambiental Brasileira: evolução histórica do Direito Ambiental. Revista de Informação Legislativa, Brasília, a. 30, n. 118, p. 191-206, p. 198, abr./jun. 1993.

3 Ibid.

4 São eles: a interdependência, equilíbrio dinâmico, natureza cíclica dos processos ecológicos, cooperação e flexibilidade e diversidade. CAPRA, Fritjof; LUISI, Pier Luigi. op. cit.

5 CAPRA, Fritjof; LUISI, Pier Luigi. op. cit., p. 435.

6 MORIN, Edgar. Os sete saberes necessários à educação do futuro. 9. ed. São Paulo: Cortez, 2004. p. 79.

7 Cf. ARAÚJO, Fernanda Castelo Branco. Articulação global-local das políticas públicas de educação ambiental na transição para o desenvolvimento sustentável: desafios e proposições com foco no município de Fortaleza. 2014. Dissertação (Mestrado em Direito) - Universidade Federal do Ceará, Fortaleza, 2014.
} 
Um aspecto da legislação, que mereceu a reflexão de Paulo Affonso Leme Machado, foi a não criação de uma disciplina específica de educação ambiental na educação formal (salvo nos cursos de extensão ou pós-graduação, conforme o artigo 10, §1ㅇ da Lei 9.975/1999), tendo em vista a necessidade de uma concepção transversal das medidas ecoeducativas. ${ }^{8}$

Esta perspectiva, se bem trabalhada, favorece uma abordagem sistêmica e também ecocêntrica, mas também traz consigo o desafio de, paradoxalmente, não deixar que as ações de educação ambiental se tornem dispersas, eventuais e assistemáticas. Para tanto, é preciso pensar em programas com metodologias e abordagens variadas, além de conteúdos mínimos obrigatórios a serem trabalhados.

Embora o dever de educação ambiental tenha sido constitucionalmente atribuído ao Poder Público, a Lei 9.795/1999 o estende às instituições educativas, aos órgãos do Sistema Nacional do Meio Ambiente, aos meios de comunicação de massa, às empresas e à sociedade como um todo.

Esta orientação normativa encontra-se em pleno acordo com o caput do artigo 225, que estabelece o dever geral da coletividade de preservar o meio ambiente para as presentes e futuras gerações, inclusive com norma constitucional mais específica, que garante a defesa contra programas, programações ou propagandas de rádio ou televisão que possam ser nocivas ao meio ambiente, nos termos do artigo 220 , §3ㄴ, II e §4으 da Constituição.

Também consta na legislação infraconstitucional o conjunto de princípios básicos da educação ambiental (artigo 4ㅇe e incisos), sendo eles: o enfoque humanista, holístico, democrático e participativo; a concepção do meio ambiente em sua totalidade, considerando a sustentabilidade e a interdependência entre o meio natural, o socioeconômico e o cultural; o pluralismo de ideias e concepções pedagógicas, na perspectiva da inter, multi e transdisciplinaridade; a vinculação entre ética, educação, trabalho e práticas sociais; a garantia de continuidade e permanência do processo educativo; a permanente avaliação crítica do processo educativo; a abordagem articulada das questões ambientais locais, regionais, nacionais e globais; o reconhecimento e o respeito à pluralidade e à diversidade individual e cultural.

Ressalte-se que a previsão de um enfoque humanista não significa uma incompatibilidade com o ecocentrismo. Afinal, como defende J. Baird Callicot, a admissão de uma ética interespecífica, que amplia o reconhecimento de valor existencial para os seres não humanos, não exclui a valia da reflexão acerca das necessidades relacionais humanas ${ }^{9}$. Trata-se de dimensões ontologicamente distintas, embora imbricadas.

Entre os nobres objetivos da Política Nacional de Educação Ambiental estão (artigo 5ㅇ): o desenvolvimento de uma compreensão integrada do meio ambiente, envolvendo aspectos ecológicos, psicológicos, legais, políticos, sociais, econômicos, científicos, culturais e éticos; a garantia de democratização das informações ambientais; o estímulo e o fortalecimento de uma consciência crítica sobre a problemática ambiental e social; o incentivo à participação individual e coletiva na preservação do meio ambiente; o estímulo à cooperação ambiental entre as diversas regiões do país, em âmbitos micro e macrorregionais; o fomento e o fortalecimento da integração com a ciência e a tecnologia; o fortalecimento da cidadania, a autodeterminação dos povos e a solidariedade como fundamentos para o futuro da humanidade.

\footnotetext{
MACHADO, Paulo Affonso Leme. Direito ambiental brasileiro. São Paulo: Malheiros, 2012. p. 176.

CALLICOTT, J. Baird. A ética da terra. In: JAMIESON, Dave (coord.). Manual de filosofia do ambiente. Lisboa: Instituto Piaget, 2003.
} 
Em conformidade com a Constituição, o atual Programa Nacional de Educação Ambiental, reformulado em 2005, possui como um de seus princípios a "concepção de ambiente em sua totalidade, considerando a interdependência sistêmica entre o meio natural e o construído, o socioeconômico e o cultural, o físico e o espiritual, sob o enfoque da sustentabilidade" (grifou-se). ${ }^{10}$

Não dá, portanto, para perder de vista a grande importância deste instrumento para a ampliação da influência do paradigma ecocêntrico.

Afinal, segundo Bosselmann, "a mudança do antropocentrismo tradicional para o ecocentrismo pode ser revolucionária em sua conceituação. Fazer a mudança, na prática, no entanto, deve ser mais evolutivo e gradual". ${ }^{11}$

Afinal, no irrenunciável cenário democrático, é a partir da progressiva sensibilização acerca dos deveres do ser humano para com a natureza que se dará a aceitação social da necessidade de redefinição dos conteúdos de certos direitos, como a consideração da sustentabilidade ecológica como condição para o exercício da livre-iniciativa.

Destaca-se, nesse sentido, o importante dever das empresas no que concerne à educação ambiental. Segundo a própria Lei 9.795/99, artigo 3ำ V, elas têm a responsabilidade de ofertar programas de capacitação de seus empregados que desemboquem em melhorias na saúde do trabalhador e no ambiente de trabalho, além de ter a possibilidade de impactar mais amplamente no processo produtivo como um todo.

Além disso, é preciso incorporar ao debate da educação ambiental no Brasil um tema que, segundo Fátima Portilho, ainda é marginalizado: a relação entre ambiente e consumo. ${ }^{12}$

Nesse supramencionado contexto de transição, os processos judiciais também podem ser apontados como importantes instrumentos de conscientização pública, ${ }^{13}$ sobretudo em tempos de crescente valorização dos precedentes judiciais no Brasil.

Destaca-se, nesse sentido, a atuação do Superior Tribunal de Justiça, cujos acórdãos em prol da defesa do meio ambiente ecologicamente equilibrado têm sido notáveis, inclusive, merecendo reconhecimento internacional. ${ }^{14}$

Ademais, é inescapável refletir que também os estudantes e os diversos profissionais do Direito devem ser público-alvo da educação ambiental formal e não formal.

\footnotetext{
10 PROGRAMA NACIONAL DE EDUCAÇÃO AMBIENTAL. Educação ambiental: por um Brasil sustentável. Brasília: Ministério do Meio Ambiente; Ministério da Educação, 2014. Disponível em: http://www.mma.gov.br/images/arquivo/80221/pronea_4edicao_web-1.pdf. Acesso em: 20 dez. 2015.

${ }^{11}$ BOSSELMANN, Klaus. O princípio da sustentabilidade: transformando direito e governança. São Paulo: Revista dos Tribunais, 2015. p. 220

12 PORTILHO, Fátima; CARNEIRO, Camila Batista Marins; GALINDO, Flávia Luzia Oliveira da Cunha. Consumo e meio ambiente: como a educação ambiental brasileira aborda essa relação? ENCONTRO NACIONAL DA ASSOCIAC̃̃̃O NACIONAL DE PÓS-GRADUAÇÃO E PESQUISA EM AMBIENTE E SOCIEDADE, 5., 2010, Florianópolis. Anais Eletrônicos [...]. Florianópolis, 2020. Disponível em: http://www.anppas.org.br/encontro5/cd/artigos/GT13-293-206-20101013115034.pdf. Acesso em: 10 jan. 2016.

${ }^{13}$ BODNAR, Zenildo. Controle jurisdicional de políticas públicas ambientais: um desafio qualificado para o Poder Judiciário. CONGRESSO NACIONAL DO CONPEDI, 18., 2009, São Paulo. Anais Eletrônicos [...]. São Paulo, .. Disponível em: http://www. publicadireito.com.br/conpedi/manaus/arquivos/anais/sao_paulo/2791.pdf. Acesso em: 14 mar. 2016.

${ }^{14}$ ESPECIALISTAS internacionais destacam protagonismo do STJ em questões ambientais. JusBrasil. Disponível em: https://stj. jusbrasil.com.br/noticias/2211827/especialistas-internacionais-destacam-protagonismo-do-stj-em-questoes-ambientais. Acesso em: 14 dez. 2016.
} 


\section{Direitos}

Democracia

Os cursos de Graduação e Pós-Graduação em Direito, as Escolas Superiores da Advocacia, da Magistratura, do Ministério Público e demais carreiras jurídicas, bem como suas respectivas associações profissionais, devem igualmente fomentar esta perspectiva em suas atividades de formação.

Nesse sentido, o Conselho Nacional de Justiça - CNJ - expediu a Recomendação n. 11, de 22/5/2007, no sentido de que os Tribunais adotem políticas públicas que tenham entre os seus objetivos a "conscientização dos próprios servidores e jurisdicionados sobre a necessidade de efetiva proteção ao meio ambiente", ${ }^{15}$ e sua promoção e recuperação, bem como para que instituam comissões para o planejamento, elaboração e acompanhamento de medidas, inclusive com fixação de metas anuais.

Ademais, além das questões relativas à gestão ambiental, também tem tido vez a reflexão sobre as próprias decisões judiciais como instrumento de proteção do meio ambiente, como ocorreu no primeiro Seminário de Planejamento Estratégico e Sustentabilidade do Poder Judiciário, em junho de 2014. ${ }^{16,17}$

\section{DESAFIOS À INTRODUÇÃO DE UMA EDUCAÇÃO AMBIENTAL ECOCÊNTRICA}

Percebe-se que ainda há que se avançar muito para a efetivação em nível satisfatório no Brasil. ${ }^{18}$ Para se ter uma ideia, a Política Nacional de Educação Ambiental foi inaugurada em 1999, 11 anos após a promulgação da Constituição. A primeira pesquisa a revelar o estado-da-arte na educação ambiental brasileira é de 2004 e abrangeu 5 Estados de 4 regiões brasileiras, com exceção do Nordeste.

Nesta ocasião, buscou-se investigar o perfil das instituições que realizam educação ambiental, quando se descobriu que está no setor público a maioria das que a põe em prática, na seguinte ordem: "órgãos federais, estaduais e municipais; escolas públicas de ensino médio e fundamental; universidades públicas, seguidas por organizações sociais (instituições da sociedade civil ou mistas, como conselhos e consórcios) e, finalmente, pelas instituições privadas".19

Quanto às atividades desenvolvidas, viu-se que as que objetivam mobilização/sensibilização são a maioria, seguidas pelas de capacitação. A modalidade "projeto" predomina sobre "programa", o que leva à conclusão de que as ações de curto e médio prazos prevalecem sobre as de longo prazo.

\footnotetext{
${ }^{5}$ CONSELHO NACIONAL DE JUSTIÇA. Recomendação 11, de 22 de maio de 2007. CNJ. Disponível em: http://www.cnj.jus.br/ busca-atos-adm?documento=1215. Acesso em: 10 jan. 2016.

${ }^{16}$ EVENTO destacou esforços e desafios do Judiciário na preservação do meio ambiente. CNJ. 9 jun. 2014. Disponível em: http://www.cnj.jus.br/noticias/cnj/61779-evento-destacou-esforcos-e-desafios-do-judiciario-na-preservacao-do-meio-ambiente. Acesso em: 10 jun. 2014.

17 Trata-se de uma preocupação de juízes de vários países, que identificaram como uma das mais importantes diretrizes do papel do Judiciário na proteção do meio ambiente uma urgente necessidade de programas de trabalho focados em educação, treinamento e desenvolvimento de informações e disseminação regional e local de colóquios judiciais sobre o assunto. Cf. KOTZÉ, Louis; PATERSON, Alexander R (org.). The Role of the Judiciary in Environmental Governance: Comparative Perspectives. New York: Kluwer Law International, 2009 (Preface).

${ }^{18}$ A responsabilidade dos entes federados na efetivação da educação ambiental é comum, cabendo à União o delineamento de diretrizes gerais sobre o assunto.

${ }^{19}$ CARVALHO, Isabel Cristina de Moura. Discutindo a educação ambiental no Brasil a partir do diagnóstico em quatro ecossistemas no Brasil. Revista Educação e Pesquisa, São Paulo, v. 31, n. 2, p. 301-313, maio/ago. 2005. Disponível em: http:// www.scielo.br/pdf/ep/v31n2/a11v31n2.pdf. Acesso em: 10 dez. 2014.
} 
Quanto à educação formal, especificamente os primeiros dados públicos sistematizados sobre a educação ambiental no Ensino Fundamental nas escolas brasileiras, estes foram colhidos entre 2001 e 2004 e apresentados em 2005 por meio do relatório "O que fazem as Escolas que dizem que fazem educação ambiental?", elaborado por algumas universidades federais.

É bem verdade que houve melhorias numéricas recentes, pois no primeiro ano em que houve o mapeamento 115 mil escolas declararam realizar algum tipo de ação e apenas 3 Estados da federação tinham cobertura de mais de 90\% de sua rede. Em 2004 já eram 152 mil escolas, e apenas quatro Estados possuíam cobertura superior a $80 \%$ e inferior a $90 \%$.

Embora possa se falar, portanto, que houve uma universalização do acesso à educação ambiental no ensino de base, esta ainda se dá de maneira inicial.

Para se ter uma ideia, o relatório mostrou que quase a metade das escolas tinha iniciado algum tipo de ação de educação ambiental apenas nos três últimos anos.

Os temas são desenvolvidos, contudo, em sua maioria, por meio de um viés fragmentado e antropocêntrico, sendo os principais pontos trabalhados: "água", "lixo e reciclagem" e "poluição e saneamento básico".

Chamou a atenção dos pesquisadores o fato de que um tema como "biomas", que teria um potencial de abordagem mais sistêmico, ser bem pouco trabalhado.

As ações práticas e transformadoras da realidade local daí decorrentes também ainda são limitadas: é o que explica o fato de que, embora tenha havido um aumento substancial da cobertura da educação ambiental, o aumento da prática de reciclagem de resíduos tenha sido de apenas três pontos percentuais. Paradoxalmente, as escolas que possuem ações de educação ambiental aumentaram em cinco pontos percentuais a prática de incineração de resíduos.

A cooperação escola-comunidade na busca de práticas sustentáveis, considerada fundamental para a consolidação de uma nova cultura ecológica, também ainda é insuficiente. ${ }^{20} \mathrm{As}$ sim, evidenciam-se contrassensos, para os quais uma das hipóteses explicativas é que ainda não se absorveu que a "educação ambiental é um processo eminentemente político que visa estimular a interpretação da realidade histórica e social, a ação transformadora e responsável e a intervenção consciente e intencional na realidade". ${ }^{21}$

Os principais dados sistematizados quanto à educação ambiental no Ensino Superior foram publicados em 2007. Participaram da pesquisa 22 Instituições de Ensino Superior - IES -, sendo 14 públicas e 8 privadas, distribuídas em 11 Estados da federação. Constatou-se que a maior parte das instituições, contrariando o formato organizacional de experiências bem-sucedidas em Universidades estrangeiras, não tem um órgão especificamente responsável pela condução da Educação Ambiental. ${ }^{22}$

\footnotetext{
${ }^{20}$ MINISTÉRIO DA EDUCAÇÃO. O que fazem as escolas que dizem que fazem educação ambiental? Brasília: Edição Eletrônica, 2007. p. 37. Disponível em: http://portal.mec.gov.br/dmdocuments/publicacao5.pdf. Acesso em: 20 dez. 2015.

${ }^{21}$ MINISTÉRIO DO MEIO AMBIENTE. Diretrizes para estratégia nacional de comunicação e educação ambiental em unidades de conservação. Brasília, 2011, p. 26. Disponível em: http://www.mma.gov.br/images/arquivo/80219/publicacao_encea. pdf. Acesso em: 20 fev. 2016.

22 ÓRGÃO GESTOR DA POLÍTICA NACIONAL DE EDUCAÇÃO AMBIENTAL. Mapeamento da educação ambiental em instituições brasileiras de educação superior: elementos para políticas públicas. Brasília, 2007. Disponível em: http://portal.mec.gov. $\mathrm{br} / \mathrm{secad} /$ arquivos/pdf/educacaoambiental/dt12.pdf. Acesso em: 17 set. 2014.
} 


\section{Hireitos \\ Humanos e}

Democracia

No que concerne à natureza das atividades desenvolvidas, as IES não desviam do padrão nacional identificado no primeiro diagnóstico sobre a Educação Ambiental no Brasil suprarreferido: o número de Programas (8) é massivamente inferior ao de Projetos (118) e as ações se concentram muito mais em projetos acadêmicos em Educação Ambiental do que propriamente em políticas institucionais sobre o tema.

Quanto ao enfoque, mais de dois terços dos projetos em educação ambiental envolveram atividades de pesquisa. Algumas se dirigiram ao ensino formal, a partir da capacitação de educadores ambientais no Ensino Fundamental e Médio, ou a comunidades. Em muitos casos, os assuntos trabalhados nos projetos são fragmentados, sendo os mais frequentes: consumo, resíduos sólidos e economia solidária.

Verificaram-se 29 cursos específicos em Educação Ambiental, sendo 14 de especialização, a maior parte deles pagos e em IES do Sudeste, e 15 de extensão, normalmente voltados para os alunos e gratuitos, feitos em parceria com outras instituições.

Afora estes, cujos enfoques programáticos relacionam-se, intrinsecamente, com o tema trabalhado, foram descritas 56 disciplinas de Educação Ambiental, sendo 38 em cursos de Graduação, uma em Pós-Graduação lato sensu e as demais em programas stricto sensu. Segundo Cristiane Derani, estes empreendimentos ainda "são vistos com desconfiança pela administração universitária, maioria dos docentes e, o que é mais incômodo, pelos destinatários da inovação, os discentes". ${ }^{23}$

Em geral,observamos também, dificuldades de construção de projetos institucionais que tomem a temática como algo coletivo, integrado e integrador do processo educativo, sendo a educação ambiental praticada de modo pontual e, portanto, desconectada do projeto pedagógico da maioria das instituições de ensino superior. ${ }^{24}$

No igual sentido de necessidade de superação destas dificuldades, estão as recomendações do Documento Técnico elaborado por pesquisadores de referência na área para orientar as políticas públicas de Educação Ambiental no Ensino Superior brasileiro:

a) institucionalização da EA na educação superior: compreende medidas e instrumentos de ambientalização das IES, em todas as suas esferas de atividade (ensino, pesquisa, extensão e gestão), que deveriam ser previstos pela política pública (entre os quais a implantação de programas de EA e de "núcleos para a aplicação da EA"); b. efeitos sobre a dinâmica institucional: contempla as modalidades de inserção da EA nas IES (transversalidade, interdisciplinaridade, complexidade, multiculturalismo, colaboração intra e interinstitucional, etc.) que a política pública deveria promover; c. produção de conhecimentos em EA e formação de pessoal especializado: diz respeito à instituição de espaços de capacitação de gestores universitários e de formação de educadores ambientais e especialistas em EA que atendam tanto à demanda interna das IES como à externa. ${ }^{25}$

\footnotetext{
${ }^{23}$ DERANI, Cristiane. Educação ambiental - um processo acadêmico? In: RODRIGUES, Horácio Wanderley; DERANI, Cristiane (org.). Educação ambiental. Florianópolis: Fundação Boiteaux, 2011. p. 57.

24 BATISTA, Maria do Socorro Silva; RAMOS, Maria da Conceição Pereira. Desafios da educação ambiental no Ensino Superior - das políticas às práticas no Brasil e em Portugal. SIMPÓSIO BRASILEIRO DE POLÍTICA E ADMINISTRAÇÃO DA EDUCAÇÃO, 25., 2011. [].26 a 30 abr. 2011. p. 3. Disponível em: http://www.anpae.org.br/simposio2011/cdrom2011/PDFs/trabalhosCompletos/comunicacoesRelatos/0356.pdf. Acesso em: 10 jul. 2014.

${ }^{25}$ ÓRGÃO GESTOR DA POLÍTICA NACIONAL DE EDUCAÇÃO AMBIENTAL. Mapeamento da educação ambiental em instituições brasileiras de educação superior: elementos para políticas públicas. Brasília, 2007, p. 27. Disponível em: http://portal.mec. gov.br/secad/arquivos/pdf/educacaoambiental/dt12.pdf. Acesso em: 17 set. 2014.
} 
No que diz respeito especificamente à educação ambiental não formal, o Ministério do Meio Ambiente possui agendas temáticas nas seguintes áreas: Programa de Educação Ambiental e Agricultura Familiar - PEAAF; ${ }^{26}$ Resíduos Sólidos; ${ }^{27}$ Unidades de Conservação; ${ }^{28}$ Ju-

${ }^{26}$ O início das atividades foi em 2009, quando se realizaram algumas oficinas e, mais recentemente, em 2012, um Seminário e lançamento do livro "Boas Práticas em Educação Ambiental na Agricultura Familiar". Em 2015, lançou-se chamada pública de parceiros para o desenvolvimento do curso "Formação de agentes populares de Educação Ambiental na Agricultura Familiar". Cf. MINISTÉRIO DO MEIO AMBIENTE. Programa de Educação Ambiental e Agricultura Familiar - PEAAF. Disponível em: http://www.mma.gov.br/educacao-ambiental/formacao/item/8267. Acesso em: 20 fev. 2016 e.

${ }^{27}$ A Estratégia Nacional de Educação Ambiental (EA) e Comunicação Social (CS) na Gestão de Resíduos Sólidos - EducaRES - é a principal ação para a instituição da Educação Ambiental no âmbito da Política Nacional de Resíduos Sólidos. Criou-se uma plataforma virtual, a qual possui cerca de 150 projetos de educação ambiental na área de resíduos sólidos. Elegeram-se 30 experiências de cada setor (público, privado e sociedade civil) para serem reconhecidas como referências nacionais em suas áreas. Cf. MINISTÉRIO DO MEIO AMBIENTE. EducaRES: práticas de educação ambiental e comunicação social em resíduos sólidos. Disponível em: http://educares.mma.gov.br/index.php/main. Acesso em: 20 fev. $2016 f$.

${ }^{28}$ Pela relevância da política conservacionista para a proteção da biodiversidade brasileira, o Ministério do Meio Ambiente instituiu a Estratégia Nacional de Comunicação e Educação Ambiental no Sistema Nacional de Unidades de Conservação da Natureza - Encea - para elaborar diretrizes para práticas de educação ambiental no momento da criação e da efetivação e no processo de gestão das Unidades. Produziu-se um mapeamento e diagnóstico das ações de educação ambiental no âmbito do Sistema Nacional de Unidades de Conservação, em 2008. Entre outros dados, destaca-se que em mais da metade (51\%) das Unidades de Conservação que participaram da pesquisa, as ações de educação ambiental ocorrem de forma pontual; em 34\% acontecem de forma contínua e em $15 \%$ não estão ocorrendo. Não se identificou uma preocupação teórico-metodológica relativamente à escolha das abordagens praticadas. As organizações não governamentais, instituições de ensino e o Poder Público Municipal, têm sido os mais importantes parceiros. Os temas e conteúdos mais frequentemente abordados são: conservação da biodiversidade e dos recursos naturais (54\%), valorização cultural e geração de renda (42,8\%), valorização da biodiversidade para a qualidade de vida (39\%) e gestão participativa e regularização fundiária $(38,2 \%)$. As maiores dificuldades apontadas são a carência de recursos financeiros e a ausência de técnicos qualificados para a realização das atividades de educação ambiental. Com base neste mapeamento, em 2011 produziu-se o documento que identifica diretrizes adequadas para nortear as ações de Educação Ambiental e Comunicação em Unidades de Conservação, que são: fortalecimento da atuação pública, estímulo e fortalecimento da participação social, estímulo à inserção da temática no ensino formal e também no ensino não formal, sobretudo que alcance os interesses da gestão da unidade e das populações em seu entorno. e qualificação da abordagem da mídia, com foco educativo na gestão ambiental. Cf.: MINISTÉRIO DO MEIO AMBIENTE. Mapeamento e diagnóstico das ações de comunicação e educação ambiental no Âmbito do Snuc. Brasília, 2008. p. 10. Disponível em: http://www.mma.gov.br/images/arquivo/80219/diagnostico_encea\%201.pdf. Acesso em: 20 fev. 2016; MINISTÉRIO DO MEIO AMBIENTE. Diretrizes para estratégia nacional de comunicação e educação ambiental em unidades de conservação. Brasília, 2011. Disponível em: http://www.mma.gov.br/images/arquivo/80219/ publicacao_encea.pdf. Acesso em: 20 fev. 2016. 


\title{
ventude e Meio Ambiente; ${ }^{29}$ Coletivos Educadores; ${ }^{30}$ Mudanças Climáticas; ${ }^{31}$ Saneamento; ${ }^{32}$
}

\author{
Gerenciamento Costeiro; ${ }^{33}$ e Licenciamento Ambiental. ${ }^{34}$
}

\begin{abstract}
${ }^{29}$ Houve, por um trabalho conjunto dos Ministérios da Educação, do Meio Ambiente e da Secretaria Nacional da Juventude, a publicação da Portaria Interministerial 319/2012, que instituiu o Grupo de Trabalho Juventude e Meio Ambiente, o qual resultou em uma proposta de texto para o Programa Nacional Juventude e Meio Ambiente, que está estruturado em quatro eixos temáticos: 1) Educação ambiental, formação e produção do conhecimento; 2) Trabalho decente e sustentável para a juventude; 3) Direito da juventude ao território; e 4) Participação social da juventude nas políticas públicas para a sustentabilidade. O Grupo foi extinto em 2013 e o material produzido está em fase de análise. Cf. MINISTÉRIO DO MEIO AMBIENTE. Programa Nacional de Juventude e Meio Ambiente. Disponível em: http://www.mma.gov.br/educacao-ambiental/formacao/item/9343. Acesso em: 20 fev. 2016a.
\end{abstract}

30 O Ministério do Meio Ambiente iniciou, em 2013, a oferta de cursos de educação ambiental a distância. Até agora foram ofertados 9 cursos e estima-se que 7.500 pessoas tenham se beneficiado diretamente desta iniciativa. A partir de 2014, o Ministério do Meio Ambiente requereu ao Programa Nacional de Acesso ao Ensino Técnico e Emprego - Pronatec - vagas em seus cursos, especialmente o Bolsa Formação, o qual oferece, gratuitamente, oportunidades nas seguintes áreas: Pronatec Ambiental, Pronatec Bolsa-Verde Extrativismo e Pronatec Catador. Cf. MINISTÉRIO DO MEIO AMBIENTE. Pronatec. Disponível em: http://www.mma.gov.br/educacao-ambiental/formacao/pronatec. Acesso em: 20 fev. 2016b.

${ }^{31}$ Tomando por mote esta temática, o Departamento de Educação Ambiental do Ministério do Meio Ambiente produziu dois documentos: um estabelecendo parâmetros e diretrizes para a Educação Ambiental no contexto das Mudanças Climáticas e outro com uma proposta de campanha sobre o tema, com respectivas estratégias de execução. Lançaram, ainda, o livro Educação e Mudanças Climáticas, por meio do qual "o Departamento de Educação Ambiental (DEA) acredita contribuir para que as ações e os projetos de EA no Brasil aprimorem a sua postura ao questionar e propor alternativas à visão ainda hegemônica de um modelo de desenvolvimento que aposta no crescimento desenfreado, na infinitude dos recursos naturais, nas soluções tecnicistas e na superutilização do ambiente", reconhecendo, "Dessa forma, [que] o cenário climático atual exige a adoção de novas escolhas no estilo de vida de nossa sociedade, mudanças de atitudes individuais e coletivas na relação com o meio natural, rupturas paradigmáticas, mudanças de valores no uso e na apropriação dos recursos e fontes energéticas e na experimentação de diferentes alternativas de postura em relação à manutenção da vida na Terra. Essas mudanças significam um imenso desafio. É notória a constatação de um distanciamento entre a compreensão do fenômeno Mudanças Climáticas e a relação com o dia-a-dia das pessoas". E, ainda, que "a interpretação e a problematização das causas e conseqüências das Mudanças Climáticas no campo conceitual e no fazer prático da EA no Brasil ainda estão emergindo. Há um conjunto de experiências pedagógicas, deliberações e propostas de EA, mas isoladas, que ainda não permitem afirmar, de forma segura, quais são os posicionamentos e sugestões apresentadas pela EA para o enfrentamento do fenômeno. [...] Podemos constatar que existem projetos e iniciativas em desenvolvimento nas instituições e organizações da sociedade civil e também no âmbito dos governos, que abordam a temática Mudança Climática pela ótica da Educação Ambiental. Na esfera do governo federal, temos a inserção da EA na regulamentação do Plano Nacional de Mudanças Climáticas; o projeto de EA no contexto das mudanças do clima e na agricultura familiar (DEA/MMA) e o programa Escola Sustentável (CGEA/MEC). Na esfera da sociedade civil, encontramos várias iniciativas, projetos, programas, cursos, entre outros, com tais temas: neutralização de carbono, seqüestro de carbono, mercado de carbono, metodologias para projetos florestais de Mecanismo de Desenvolvimento Limpo (MDL) etc." MINISTÉRIO DO MEIO AMBIENTE. Educação ambiental e mudanças climáticas: diálogo necessário num mundo em transição. Brasília, 2013, passim. Disponível em: http://www.mma.gov.br/images/arquivo/80062/Livro\%20EA\%20e\%20Mudancas\%20Climaticas_WEB.pdf. Acesso em: 20 fev. 2016.

${ }^{32}$ Tem-se atuado em conjunto com o Ministério das Cidades, responsável pela introdução da Política Nacional de Saneamento Básico, por meio da produção de cartilhas, oficinas e Seminários. Cf. MINISTÉRIO DO MEIO AMBIENTE. Saneamento. Disponível em: http://www.mma.gov.br/educacao-ambiental/formacao/item/365. Acesso em: 20 fev. 2016c.

33 O Ministério do Meio Ambiente contratou uma consultoria para elaborar uma proposta de curso de formação em Gerenciamento Costeiro, que está em andamento desde 2014. MINISTÉRIO DO MEIO AMBIENTE. Gerenciamento costeiro. Disponível em: http://www.mma.gov.br/educacao-ambiental/formacao/item/10430. Acesso em: 20 fev. 2016d.

${ }^{34}$ Realizou-se um estudo nacional para avaliar como a Educação Ambiental vem sendo utilizada para mitigação de impactos ambientais no âmbito dos procedimentos de Licenciamento Ambiental nas esferas federal e estadual. Seguem alguns trechos da publicação: "Durante os relatos, algumas instituições se mostraram preocupadas com a fragilidade da Educação Ambiental no âmbito do licenciamento, alegando que ela não está cumprindo os objetivos da própria EA. [...] existem diversos tipos e formas de atuação, sendo que o que prevalece ainda são ações educativas pontuais e muitas vezes sem contexto, simplesmente para o cumprimento da condicionante. Apesar de tudo, foi possível observar também, que neste meio, mesmo regido pelo poder econômico e pela demanda de mercado, existem instituições com comprometimento real de transformação das comunidades. [...] Neste sentido, muitos empreendimentos, sabendo da falta de acompanhamento e fiscalização dos programas, aproveitam-se da situação para reduzirem as ações ou até mesmo interromperem os programas[...] As instituições informaram que alguns empreendimentos adotam este procedimento como uma estratégia para reduzirem os gastos, e como não há um acompanhamento efetivo dos órgãos ambientais, não existe um mecanismo de cobrança dos empreendimentos em relação à continuidade da execução dos programas.[...] Algumas instituições enfatizaram que o acompanhamento dos PEAs [Programas de Educação Ambiental] pelos órgãos estaduais é praticamente inexistente. [...] Na visão de algumas empresas de consultoria, os PEAs deveriam surgir inicialmente como condicionante do licenciamento, mas que seria um caminho natural à continuidade destes como programas de responsabilidade social dos empreendimentos. Enfatizaram que esta transição garantiria a continuidade dos processos, mas que só seria possível se os empreendedores compreendessem o real conceito de responsabilidade social. Hoje, estes projetos, em geral, têm a finalidade de promover e melhorar a imagem das empresas nas comunidades". MINISTÉRIO DO MEIO AMBIENTE. Produto 4: Documento técnico contendo levantamento realizado com instituições executoras dos programas e projetos de 
Ainda inexistem dados sistematizados sobre o conjunto das iniciativas de educação ambiental não formal. Alguns relatórios e documentos técnicos oficiais apontam para iniciativas que estão sendo desenvolvidas, mas que ainda parecem longe de abranger o universo populacional necessário ou de compilar dados robustamente representativos em todos os Estados da federação.

Na prática, assim, não é possível fazer uma avaliação esmiuçada acerca da efetividade destas políticas ou refletir de modo amplo acerca de mecanismos de permanente aperfeiçoamento.

Mesmo nos casos em que há dados, é preciso que se olhe para eles com muita cautela, pois são incrivelmente lacunosos e estão longe de possuir uma representatividade adequada, o que faz com que qualquer análise generalizante deva ser feita com muitas ponderações e reservas. Ainda, é injustificável que estes dados não tenham sido atualizados e ampliados.

As ações mapeadas na educação formal ou não formal, de uma maneira geral, possuem, na maioria das vezes, caráter pontual e não programático, o que interfere significativamente em seu potencial transformador, aproximando-as de políticas de valor cosmético.

Os conteúdos abordados, embora muitas vezes contemplem questões locais, relevantes para populações vulneráveis a injustiças ambientais, também são, muitas vezes, fragmentados em razão de recursos ambientais específicos, não oportunizando, de maneira adequada, o salto necessário para a compreensão da dimensão complexa das inter-relações constitutivas dos ecossistemas e para uma avaliação acerca da adequação de comportamento dos mais diversos grupos das sociedades humanas diante desta realidade.

A formação de educadores ambientais também ainda não supre a demanda existente e enfrenta desafios. Segundo Isabel Carvalho,

Essa situação é ilustrada, por exemplo, no diagnóstico da REPEA, que descreve a grande mobilidade de um segmento importante de educadores ambientais em São Paulo, em sua maioria jovens e recém-formados, que transitam entre vários projetos de conforme a disponibilidade de recursos públicos e privados que os apóiam e aprovam ou não. ${ }^{35}$

Neste contexto, ainda se tem de lidar com um grande questionamento: Como formar educadores críticos, libertos da "razão instrumental, utilitária e segmentada", ${ }^{36}$ aptos a apreender os fenômenos por meio do paradigma da complexidade? Como concretizar isso num contexto de um Estado de atuação contraditória, muitas vezes subordinando-se aos interesses dos grandes degradadores?

educação ambiental em desenvolvimento no país, como exigência dos licenciamentos ambientais federal e estaduais. 30 out. 2015, passim. Disponível em: http://www.mma.gov.br/images/arquivo/80221/produto\%204\%20EA\%20no\%20licenciamento\%20executoras\%20final.pdf. Acesso em: 1ㅇ mar. 2016.

${ }^{35}$ CARVALHO, Isabel Cristina de Moura. Discutindo a educação ambiental no Brasil a partir do diagnóstico em quatro ecossistemas no Brasil. Revista Educação e Pesquisa, São Paulo, v. 31, n. 2, p. 301-313, p. 311, maio/ago. 2005. Disponível em: http://www.scielo.br/pdf/ep/v31n2/a11v31n2.pdf. Acesso em: 10 dez. 2014.

36 DERANI, Cristiane. Educação ambiental - um processo acadêmico? In: RODRIGUES, Horácio Wanderley; DERANI, Cristiane (org.). Educação ambiental. Florianópolis: Fundação Boiteaux, 2011. p. 51. 
É possível, diante desse cenário, apontar para um forte indício de não priorização e de precarização desta política. ${ }^{37}$

\section{CONCLUSÃO}

Assim, percebe-se que a educação ambiental no Brasil está tomando forma, a qual, paradoxalmente, pode estar ruindo antes de se soerguer. A situação fica ainda mais grave diante de uma série de desmontes que o sistema jurídico de proteção ambiental vem sofrendo no Brasil nos últimos tempos.

Assim, percebe-se que é preciso haver uma postura mais incisiva do Estado. Embora o artigo 2ㅇ da Lei de Política Nacional de Educação Ambiental preveja que a educação ambiental é um componente essencial e permanente da educação nacional, e que deve estar presente em todos os níveis de ensino formal e também na educação não formal, questiona-se se os instrumentos existentes podem, de fato, alcançar a universalização do acesso à educação ambiental e resultar em efetivas transformações de mundivisão, que possibilitem o embasamento de uma nova relação com o entorno.

Os documentos e estudos técnicos aqui citados revelam diagnósticos, pareceres e sugestões de diretrizes, o que é um passo necessário e preliminar para o planejamento e execução de novas tarefas.

Além disso, realiza-se por uma dimensão jurídica importantíssima. Afinal, a Educação Ambiental é um dever fundamental do Estado, e, como tal, exige que se tome uma série de providências, por meio de prestações positivas, sob pena de responsabilidade.

Caso contrário, "se resumiria em uma estética ou, o que é muito mais perverso, numa retórica da práxis ambiental". ${ }^{38}$ É essencial, assim, a garantia e o fortalecimento de sua "presença subversiva" ${ }^{39}$ no âmbito institucional, não por meio de um discurso normativo e político de tonalidades suaves, mas, sim, que sejam revestidos e marcados por imperatividade e coercibilidade.

Nesse sentido, foi importante a inclusão, em 2012, do §7으 no artigo 26 da Lei de Diretrizes e Bases da Educação Brasileira - Lei n. 9.394/1996 -, determinando que os princípios da educação ambiental devem ser incluídos de forma integrada como conteúdo obrigatório nos currículos dos Ensinos Fundamental e Médio.

Entende-se, contudo que as legislações infraconstitucionais que preveem as políticas de educação ambiental ainda podem e devem ser mais específicas e prever metas de universalização do acesso e, ainda, detalhando conteúdos mínimos a serem abordados de forma interdisciplinar e holística, a exemplo de um dos maiores desafios de nossos tempos: as mudanças climáticas.

\footnotetext{
37 CARVALHO, Isabel Cristina de Moura. Discutindo a educação ambiental no Brasil a partir do diagnóstico em quatro ecossistemas no Brasil. Revista Educação e Pesquisa, São Paulo, v. 31, n. 2, p. 301-313, maio/ago. 2005. Disponível em: http:// www.scielo.br/pdf/ep/v31n2/a11v31n2.pdf. Acesso em: 10 dez. 2014.

38 DERANI, Cristiane. Educação ambiental - um processo acadêmico? In: RODRIGUES, Horácio Wanderley; DERANI, Cristiane (org.). Educação ambiental. Florianópolis: Fundação Boiteaux, 2011. p. 44.

${ }^{39}$ DERANI, op. cit., p. 55.
} 
Não se pode, portanto, perder de vista a grande importância da sensibilização de todos para a ascensão gradual do paradigma ecocêntrico, considerando que isso não se fará a partir de conteúdos fragmentados ou sem que se garanta o amplo conhecimento da população acerca dos atuais dilemas civilizatórios.

Nesse sentido, compreende-se que é fundamental que o Estado adote diretrizes políticas e legislativas de orientação ecocêntrica, com a finalidade de sensibilizar as gerações presentes e futuras e instigá-las a repensar o lugar do ser humano na natureza e possibilitar, de tal modo, uma metamorfose ${ }^{40}$ ou uma transição ecocêntrica democrática.

Não se deve, porém, deixar iludir: embora fundamental, a integração do elemento ecológico aos aspectos social e econômico do ordenamento jurídico é uma medida inicial diante de uma longa trajetória até se alcançar o ser-ainda-não da sustentabilidade.

\section{REFERÊNCIAS}

ARAÚJO, Fernanda Castelo Branco. Articulação global-local das políticas públicas de educação ambiental na transição para o desenvolvimento sustentável: desafios e proposições com foco no município de Fortaleza. 2014. Dissertação (Mestrado em Direito) - Universidade Federal do Ceará, Fortaleza, 2014.

BATISTA, Maria do Socorro Silva; RAMOS, Maria da Conceição Pereira. Desafios da educação ambiental no Ensino Superior - das políticas às práticas no Brasil e em Portugal. SIMPÓSIO BRASILEIRO DE POLÍTICA E ADMINISTRAÇÃO DA EDUCAÇÃO, 25., 2011. Anais Eletrônicos [...]. 26 a 30 abr. 2011, p. 3. Disponível em: http://www.anpae. org.br/simposio2011/cdrom2011/PDFs/trabalhosCompletos/comunicacoesRelatos/0356.pdf. Acesso em: 10 jul. 2014.

BODNAR, Zenildo. Controle jurisdicional de políticas públicas ambientais: um desafio qualificado para o Poder Judiciário. CONGRESSO NACIONAL DO CONPEDI, 18., 2009, São Paulo. Anais Eletrônicos [...]. São Paulo, 4 a 7 nov. 2009. p. 2.279. Disponível em: http://www.publicadireito.com.br/conpedi/manaus/arquivos/anais/sao_paulo/2791.pdf. Acesso em: 14 mar. 2016.

BOSSELMANN, Klaus. O princípio da sustentabilidade: transformando direito e governança. São Paulo: Revista dos Tribunais, 2015. p. 220.

CALLICOTT, J. Baird. A ética da terra. In: JAMIESON, Dave (coord.). Manual de filosofia do ambiente. Lisboa: Instituto Piaget, 2003.

CAPRA, Fritjof; LUISI, Pier Luigi. A visão sistêmica da vida: uma concepção unificada e suas implicações filosóficas, políticas, sociais e econômicas. São Paulo: Cultrix, 2014.

CARVALHO, Isabel Cristina de Moura. Discutindo a educação ambiental no Brasil a partir do diagnóstico em quatro ecossistemas no Brasil. Revista Educação e Pesquisa, São Paulo, v. 31, n. 2, p. 301-313, maio/ago. 2005. Disponível em: http://www.scielo.br/pdf/ep/v31n2/a11v31n2.pdf. Acesso em: 10 dez. 2014.

CONSELHO NACIONAL DE JUSTIÇA. Recomendação 11, de 22 de maio de 2007. CNJ. Disponível em: http://www. cnj.jus.br/busca-atos-adm?documento=1215. Acesso em: 10 jan. 2016.

\footnotetext{
40 "A ideia de metamorfose, mais rica do que a ideia de revolução, guarda a radicalidade transformadora, mas a liga à conservação (da vida, do patrimônio cultural). Para ir rumo à metamorfose, como mudar de caminho? Mas se parece possível corrigir alguns males, é impossível romper a lógica técnico-científico-econômico-civilizacional que leva o planeta ao desastre. No entanto, a História humana mudou muitas vezes de caminho. Tudo recomeça por uma inovação, uma nova mensagem desviante, marginal, pequena, muitas vezes invisível para os contemporâneos. Assim começaram as grandes religiões: budismo, cristianismo, islamismo. O capitalismo se desenvolveu parasitando as sociedades feudais para finalmente decolar e, com a ajuda de monarquias, desintegrá-las. A ciência moderna formou-se a partir de algumas mentes desviantes dispersas, Galileu, Bacon, Descartes, e então criou suas redes e associações, se introduziu nas universidades no século XIX, e depois, no século XX nas economias e nos Estados para se tornar um dos quatro poderosos motores da nave espacial Terra. O socialismo nasceu de algumas mentes autodidatas e marginalizadas no século XIX para se tornar uma formidável força histórica no século XX. Hoje, tudo tem que ser repensado. Tudo deve recomeçar. Com efeito, tudo começou, mas sem que se soubesse. Estamos no estágio de começos, modestos, invisíveis, marginais, dispersos. Porque já existe, em todos os continentes, uma efervescência criativa, uma multiplicidade de iniciativas locais, em conformidade com a revitalização econômica, ou social, ou política, ou cognitiva, ou educacional ou ética, ou da reforma da vida". MORIN, Edgar. Elogio da metamorfose. Instituto Humanitas Unisinos. 11 jan. 2010. Disponível em: http://www.ihu.unisinos.br/noticias/28829-elogio-da-metamorfose-artigo-de-edgar-morin. Acesso em: 15 ago. 2014.
} 
DERANI, Cristiane. Educação ambiental - um processo acadêmico? In: RODRIGUES, Horácio Wanderley; DERANI, Cristiane (org.). Educação ambiental. Florianópolis: Fundação Boiteaux, 2011.

ESPECIALISTAS internacionais destacam protagonismo do STJ em questões ambientais. JusBrasil. Disponível em: https://stj.jusbrasil.com.br/noticias/2211827/especialistas-internacionais-destacam-protagonismo-do-stj-em-questoes-ambientais. Acesso em: 14 dez. 2016.

EVENTO destacou esforços e desafios do Judiciário na preservação do meio ambiente. CNJ. 9 jun. 2014. Disponível em: http://www.cnj.jus.br/noticias/cnj/61779-evento-destacou-esforcos-e-desafios-do-judiciario-na-preservacao-do-meio-ambiente. Acesso em: 10 jun. 2014.

KOTZÉ, Louis; PATERSON, Alexander R (org.). The Role of the Judiciary in Environmental Governance: Comparative Perspectives. New York: Kluwer Law International, 2009 (Preface).

MACHADO, Paulo Affonso Leme. Direito ambiental brasileiro. São Paulo: Malheiros, 2012.

MINISTÉRIO DA EDUCAÇÃO. O que fazem as escolas que dizem que fazem educação ambiental? Brasília: Edição Eletrônica, 2007. p. 37. Disponível em: http://portal.mec.gov.br/dmdocuments/publicacao5.pdf. Acesso em: 20 dez. 2015.

MINISTÉRIO DO MEIO AMBIENTE. Diretrizes para estratégia nacional de comunicação e educação ambiental em unidades de conservação. Brasília, 2011. Disponível em: http://www.mma.gov.br/images/arquivo/80219/publicacao_encea.pdf. Acesso em: 20 fev. 2016.

MINISTÉRIO DO MEIO AMBIENTE. Gerenciamento costeiro. Disponível em: http://www.mma.gov.br/educacao-ambiental/formacao/item/10430. Acesso em: 20 fev. 2016.

MINISTÉRIO DO MEIO AMBIENTE. Mapeamento e diagnóstico das ações de comunicação e educação ambiental no âmbito do SNUC. Brasília, 2008. p. 10. Disponível em: http://www.mma.gov.br/images/arquivo/80219/diagnostico_encea\%201.pdf. Acesso em: 20 fev. 2016.

MINISTÉRIO DO MEIO AMBIENTE. Produto 4: documento técnico contendo levantamento realizado com instituições executoras dos programas e projetos de educação ambiental em desenvolvimento no país, como exigência dos licenciamentos ambientais federal e estaduais. 30 out. 2015, passim. Disponível em: http://www.mma.gov. br/images/arquivo/80221/produto\%204\%20EA\%20no\%20licenciamento\%20executoras\%20final.pdf. Acesso em: 10 mar. 2016.

MINISTÉRIO DO MEIO AMBIENTE. Programa Nacional de Juventude e Meio Ambiente. Disponível em: http:// www.mma.gov.br/educacao-ambiental/formacao/item/9343. Acesso em: 20 fev. 2016a.

MINISTÉRIO DO MEIO AMBIENTE. Pronatec. Disponível em: http://www.mma.gov.br/educacao-ambiental/formacao/pronatec. Acesso em: 20 fev. 2016b.

MINISTÉRIO DO MEIO AMBIENTE. Saneamento. Disponível em: http://www.mma.gov.br/educacao-ambiental/ formacao/item/365. Acesso em: 20 fev. 2016c.

MINISTÉRIO DO MEIO AMBIENTE. Educação ambiental e mudanças climáticas: diálogo necessário num mundo em transição. Brasília, 2013, passim. Disponível em: http://www.mma.gov.br/images/arquivo/80062/Livro\%20 EA\%20e\%20Mudancas\%20Climaticas_WEB.pdf. Acesso em: 20 fev. 2016d.

MINISTÉRIO DO MEIO AMBIENTE. Programa de Educação Ambiental e Agricultura Familiar - PEAAF. Disponível em: http://www.mma.gov.br/educacao-ambiental/formacao/item/8267. Acesso em: 20 fev. 2016e.

MINISTÉRIO DO MEIO AMBIENTE. EducaRES: práticas de educação ambiental e comunicação social em resíduos sólidos. Disponível em: http://educares.mma.gov.br/index.php/main. Acesso em: 20 fev. $2016 f$.

MORIN, Edgar. Elogio da metamorfose. Instituto Humanitas Unisinos. 11 jan. 2010. Disponível em: http://www. ihu.unisinos.br/noticias/28829-elogio-da-metamorfose-artigo-de-edgar-morin. Acesso em: 15 ago. 2014.

MORIN, Edgar. Os sete saberes necessários à educação do futuro. 9. ed. São Paulo: Cortez, 2004.

ÓRGÃO GESTOR DA POLÍTICA NACIONAL DE EDUCAÇÃO AMBIENTAL. Mapeamento da educação ambiental em instituições brasileiras de educação superior: elementos para políticas públicas. Brasília, 2007. Disponível em: http://portal.mec.gov.br/secad/arquivos/pdf/educacaoambiental/dt12.pdf. Acesso em: 17 set. 2014.

PORTILHO, Fátima; CARNEIRO, Camila Batista Marins; GALINDO, Flávia Luzia Oliveira da Cunha. Consumo e meio ambiente: como a educação ambiental brasileira aborda essa relação? ENCONTRO NACIONAL DA ASSOCIAÇÃO NACIONAL DE PÓS-GRADUAÇÃO E PESQUISA EM AMBIENTE E SOCIEDADE, 5., 2010, Florianópolis. Anais eletrônicos [...]. Florianópolis, 2010. Disponível em: http://www.anppas.org.br/encontro5/cd/artigos/GT13-293206-20101013115034.pdf. Acesso em: 10 jan. 2016. 
PROGRAMA NACIONAL DE EDUCAÇÃO AMBIENTAL. Educação ambiental: por um Brasil sustentável. Brasília: Ministério do Meio Ambiente; Ministério da Educação, 2014. Disponível em: http://www.mma.gov.br/images/arquivo/80221/pronea_4edicao_web-1.pdf. Acesso em: 20 dez. 2015.

WAINER, Ann Helen. Legislação Ambiental Brasileira: evolução histórica do Direito Ambiental. Revista de Informação Legislativa, Brasília, a. 30, n. 118, p. 191-206, abr./jun. 1993. 